\title{
Racismo e Antirracismo: Ampliando o Debate
}

KARL MONSMA*

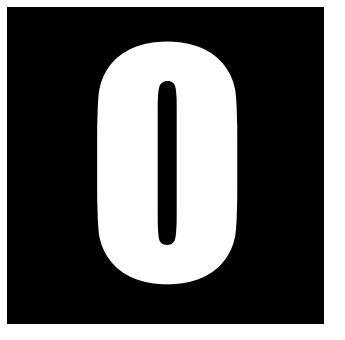

propósito deste número da revista é ampliar o debate sobre racismo e antirracismo no Brasil para além da questão das cotas para o ingresso no ensino superior, que tem dominado a discussão nos últimos anos. Com os artigos publicados aqui sobre diferentes formas de racismo, em contextos distintos, e contra vários grupos racializados, espera-se aprofundar as discussões sobre a natureza e variedades do racismo. Se o racismo permeia as instituições e a cultura brasileiras, é importante entender como ele funciona, quais são suas consequências e como estas se concatenam, bem como os processos envolvidos na continuidade e nas transformações do racismo, especialmente os processos de reprodução intergeracional deste fenômeno. Todo isso é necessário para pensar intervenções eficazes em vários níveis para eliminar, ou pelo menos coibir, o racismo e amenizar seus efeitos. Uma das consequências da predominância da questão das cotas universitárias nos debates é certa tendência de negligenciar outras intervenções talvez igualmente importantes. Pode-se elaborar uma longa lista de tais intervenções, mas alguns exemplos de

* Universidade Federal do Rio Grande do Sul (Brasil) 
metas importantes seriam coibir a violência policial contra jovens negros, impedir e punir a violência de fazendeiros contra povos indígenas, eliminar a discriminação contra bairros das periferias no fornecimento de serviços públicos, priorizar o investimento nas escolas públicas das periferias, eliminar a discriminação racial no mercado de trabalho, assegurar os direitos de empregadas domésticas e trabalhadores migratórios, proteger os direitos à terra dos indígenas e dos quilombolas, eliminar a discriminação racial no acesso ao crédito de cooperativas e de pequenos empreendedores, eliminar as representações negativas de negros e indígenas na esfera pública, reconhecer as contribuições de negros e indígenas para a construção do Brasil nos monumentos, museus e livros escolares.

Este dossiê não pretende ser abrangente, só levanta algumas questões relativamente pouco abordadas na pesquisa sociológica brasileira, como as consequências do racismo para a saúde física e mental, a natureza da retórica conservadora usada para argumentar contra políticas antirracistas, as relações entre representações da história nacional e noções do que o país deve ou não aos grupos historicamente racializados e excluídos, e as relações entre as migrações e as desigualdades raciais. $\mathrm{O}$ dossiê também inclui artigos com evidências comparativas relativamente desconhecidas no Brasil, inclusive sobre a questão das cotas no ensino superior, que discutem várias formas e consequências do racismo contra grupos distintos nos EUA, no Canadá, na União Europa, na Índia, na Austrália e em Nova Zelândia, além do Brasil.

Richard Lempert, professor aposentado da Faculdade de Direito da Universidade de Michigan e do Departamento de Sociologia dessa mesma universidade, foi o autor principal da política de ação afirmativa dessa faculdade, que virou alvo de um processo importante na Suprema Corte dos Estados Unidos, e é um dos principais defensores de tais políticas. Lempert já escreveu várias petições amicus curiae para instruir processos pertinentes no Suprema Corte. Além de conhecer bem a jurisprudência a 
respeito, ele conhece os debates sociocientíficos sobre as consequências da ação afirmativa, tendo sido por muitos anos professor do Programa de Pós-Graduação em Sociologia da Universidade de Michigan e, depois disso, diretor da Divisão de Ciências Sociais e Econômicas da Fundação Nacional de Ciências dos Estados Unidos.

No seu artigo, depois de resumir a história da jurisprudência sobre as ações afirmativas, discute os debates sociocientíficos e estatísticos sobre a eficácia da ação afirmativa no ensino superior, detendo-se especialmente no caso das faculdades de direito. É importante o leitor saber que os cursos profissionais mais concorridos nos Estados Unidos, como direito, medicina e administração, são cursos de pós-graduação, não de graduação como no Brasil, e cada área tem uma prova padronizada nacional, cujos resultados, junto com o histórico escolar da graduação, determinam a maior parte das chances do aceite, especialmente nas faculdades mais concorridas. Muita da jurisprudência a respeito da ação afirmativa decorre de processos encetados por brancos que não foram selecionados, e que alegam que "suas" vagas foram ocupadas por negros, latinos ou indígenas que ingressaram por programas de ação afirmativa. O resultado principal desses processos é que cotas para minorias foram proibidas como inconstitucionais em 1978 pela Suprema Corte dos Estados Unidos, ironicamente por violarem, na opinião dos juízes, a cláusula garantindo a "proteção igual" da lei para todos os cidadãos, da 14르 emenda à constituição, que foi aprovada na esteira da Guerra Civil para garantir a cidadania dos ex-escravizados. Entretanto, a corte deixou aberta a possibilidade de as universidades usarem sistemas de prioridade para minorias com o fim de contribuir para a diversidade do corpo estudantil e assim melhorar a experiência didática para todos. É isso que universidades em todo o país fizeram nas últimas décadas, embora alguns estados tenham aprovado plebiscitos populares proibindo qualquer consideração de raça, cor ou etnicidade nas decisões de seleção, o que acabou com o novo sistema 
nesses estados e levou a uma busca por outras maneiras de pontuar os candidatos que dessem uma ajuda aos alunos das minorias.

A pesquisa sociológica e econométrica entrou nos processos judiciais, por meio, principalmente, das petições amicus curiae escritas por cientistas sociais. Boa parte da controvérsia social científica centra-se na hipótese de "disparidade" levantada por alguns críticos, segundo a qual a ação afirmativa promove o fracasso dos beneficiários ao colocá-los em faculdades onde a grande maioria de seus colegas brancos é nitidamente melhor preparada. Isso resultaria em problemas de baixo desempenho, frustração, baixa autoestima e evasão entre os beneficiários, especialmente os negros, que teriam mais chances de sucesso nas faculdades com mais fácil ingresso, onde as qualificações e a formação anterior desses alunos negros seriam mais semelhantes às de seus colegas brancos. Lempert aponta vários problemas estatísticos nessa literatura e apresenta evidências contundentes de outras pesquisas mostrando que os resultados da ação afirmativa são exatamente o contrário. Os beneficiários têm chances de sucesso nitidamente melhores quando colocados em faculdades meIhores, mesmo quando suas qualificações de ingresso são muito abaixo da média para suas faculdades. Lempert também apresenta evidências de que, depois de se formarem nas faculdades profissionais, como as de direito, os negros e outros beneficiários da ação afirmativa têm chances iguais às dos colegas de sucesso na carreira.

Uma variedade mais recente dessa crítica da "disparidade" alega que o problema aparece especialmente nos cursos das ciências exatas e nas engenharias, porque muitos negros que ingressam nas universidades pretendendo estudar nessas áreas desistem depois. ${ }^{1}$ Lempert aponta, entretanto, que os alunos brancos que inicialmente querem cursar as exatas

\footnotetext{
${ }^{1}$ Nos EUA, os alunos de graduação são aceitos pela universidade, não por cursos específicos, e só escolham formalmente o curso depois de dois anos de estudos mais gerais.
} 
também desistem em grandes números, principalmente porque os professores nessas áreas são mais rigorosos nas avaliações e um bom número de alunos é reprovado ou ganha conceitos baixos, resultando em certo desânimo. Em geral, esses alunos não desistem da universidade, só migram para outras áreas. No caso dos negros e outras minorias, ainda outra influência é a atração dos cursos nas ciências sociais e humanas, que oferecem disciplinas, e até cursos específicos, que focalizam sua experiência e questões como racismo e desigualdades sociais. Novamente, Lempert apresenta evidências de que as chances de se formar nas exatas ou engenharias são meIhores quando as minorias estudam nas universidades ou faculdades mais seletivas, provavelmente porque essas instituições focalizam mais os alunos da graduação e oferecem mais serviços de apoio aos alunos. Esse resultado é o contrário do que alegam os críticos da ação afirmativa.

Finalmente, Lempert discute as pesquisas avaliando se a ação afirmativa baseada na classe social pode servir bem para promover o acesso de negros e outras minorias às universidades. Embora tais programas tenham certo grau de sucesso em selecionar alunos negros e de outras minorias, especialmente quando priorizam alunos com desempenho excepcional relativo aos colegas das mesmas escolas ou relativo ao que se espera de um aluno nas mesmas circunstâncias sociais, Lempert conclui que sistemas de priorização por classe social são muito ineficientes em promover o acesso das minorias. Especialmente no contexto dos Estados Unidos, onde quase todas as universidades são pagas e a maioria dos pobres é branca (porque a grande maioria da população é branca), a ação afirmativa baseada somente na classe social em escala o suficiente para permitir o acesso de um bom número de negros e outras minorias, igual ao número que ingressa com a ação afirmativa racial, seria muito cara para as universidades, porque seriam necessárias bolsas para o enorme número de brancos aceitos sem condições para custear sua formação. 
No Brasil, tal forma de ação afirmativa baseada somente na classe social não implicaria tantos custos adicionais no caso das universidades públicas, porque estas são gratuitas. Entretanto a proporção de alunos negros aceitos sob esse sistema provavelmente continuaria bem abaixo da sua proporção na população, primeiro porque uma parte das vagas $50 \%$ no atual sistema - continuaria a ser ocupado por alunos selecionados por critérios universais, que somente permitem o ingresso de um número pequeno de negros; segundo, porque mesmo entre aqueles selecionados por ação afirmativa baseada na classe social - por exemplo, entre egressos de escolas públicas - haveria uma sub-representação de negros, em função da estratificação racial dentro das classes populares, com os negros concentrados nos bairros mais pobres, nos empregos mais precários e nas piores escolas. Somente um sistema de ação afirmativa por classe social bem mais detalhado, levando em conta, além da renda familiar, variáveis como a qualidade da escola onde o aluno se formou e as características do bairro onde mora, seria capaz de promover o ingresso de mais alunos negros, e mesmo assim pode favorecer os brancos.

Lempert também aponta que a ação afirmativa baseada na classe arrisca deixar fora das boas universidades muitos dos negros mais bem preparados para o ensino superior, porque estes muitas vezes são de famílias com condições econômicas um pouco melhores e não seriam beneficiados pela ação afirmativa baseada na classe, mas ao mesmo tempo não se beneficiaram de uma formação anterior de qualidade suficiente para assegurar o ingresso nas melhores faculdades sem a ação afirmativa. Ou seja, com a ação afirmativa baseada somente na classe social, as melhores universidades ficariam com alguns alunos negros, mas muito menos de que teriam com prioridades raciais, e esses alunos seriam menos bem preparados, na média, que alunos aceitos por meio de um sistema de ação afirmativa racial. Os negros mais bem preparados seriam forçados 
a estudar em faculdades de menor qualidade, onde teriam chances menores de sucesso nos estudos e na vida profissional posterior. Este último ponto é bem pertinente ao Brasil, onde o sistema de cotas atual combina critérios de cor e classe, e não contempla os negros que estudaram em escolas particulares, que em muitos casos são mais bem preparados que outros alunos negros, mas não alcançam notas no vestibular ou no ENEM altas o suficiente para passar nas universidades públicas pela seleção universal, especialmente nos cursos mais disputados, e precisam estudar em faculdades particulares. Com isso muitos dos alunos negros mais bem preparados acabam recebendo uma formação inferior.

João Feres Jr. é professor de Ciência Política no IESP-UERJ e se dedica a pesquisas sobre a história dos conceitos e sobre os argumentos e representações a respeito da ação afirmativa que aparecem na mídia. Para este número ele colabora com um artigo em coautoria com Verônica Daflon comparando os argumentos contra a ação afirmativa proferidos por oponentes acadêmicos dessas políticas na Índia e no Brasil. Apesar de várias diferenças entre os dois países, principalmente na natureza dos grupos beneficiados e no tempo de existência da ação afirmativa, muito maior na Índia, Feres Jr. e Daflon encontram estratégias retóricas parecidas, que se encaixam nas categorias da retórica reacionária propostas por Albert Hirschman. O que distingue este tipo de argumento, segundo os autores, é que visa impedir ou reverter mudanças, argumentando que produzirão resultados contrários do esperado, que resultarão em consequências negativas maiores que o valor de seus benefícios ou que serão ineficazes.

Feres e Daflon apontam que os oponentes da ação afirmativa raramente discutem evidências empíricas, e geralmente baseiam seus argumentos nos supostos danos futuros de tais políticas. Parece que esses argumentos ganham força pelo uso de estratégias retóricas já disponíveis na cultura discursiva dos respectivos países e reconhecidas como formas 
de argumentação legítimas pelos leitores, apesar de dispensar evidências empíricas. Os autores argumentam que as políticas de ação afirmativa devem ser implementadas de forma flexível e pragmática, com avaliação regular e modificações para enfrentar os problemas que surgem. Este breve artigo não especula sobre os motivos pela oposição desses intelectuais às políticas de ação afirmativa, mas nota que muitos deles são brancos, no Brasil, ou das castas dominantes, na Índia.

David R. Williams, professor de Saúde Pública, Sociologia e Estudos Africanos e Afro-Americanos na Universidade Harvard, afiliado também ao Departamento de Psiquiatria e Saúde Mental da Universidade de Cape Town, África do Sul, é um dos mais citados sociólogos do mundo, especializado faz muito tempo na pesquisa sobre as consequências do racismo para a saúde dos integrantes de grupos humanos estigmatizados e discriminados. No artigo apresentado aqui, ele e sua coautora Naomi Priest, da Universidade Nacional da Austrália, sintetizam os resultados de um grande número de pesquisas empíricas sobre racismo e saúde, principalmente nos Estados Unidos, no Canadá, na União Europeia (sobretudo o Reino Unido), na Austrália e na Nova Zelândia, discutindo as formas do racismo e os caminhos levando delas a consequências adversas para a saúde mental e física das vítimas do racismo.

Além da vasta literatura sintetizada, que em si mesma deve ser útil aos pesquisadores brasileiros, o artigo é notável pela ênfase nas várias formas do racismo, divididos aqui entre racismo institucional, racismo cultural e experiências de discriminação racista, em vários contextos nacionais, além dos múltiplos processos pelos quais o racismo influencia a saúde. A mensagem central do artigo é clara: o racismo influencia fortemente a saúde, e de múltiplas maneiras que se combinam e interagem ao longo da vida, produzindo sofrimento desnecessário, expectativa de vida diminuída e muitas oportunidades perdidas para as populações racialmente 
estigmatizadas. O artigo é notável também por apresentar os resultados de pesquisas envolvendo vários grupos racializados, como os aborígenes e imigrantes da Austrália, os Maori da Nova Zelândia e os roma ("ciganos") e imigrantes da Europa, além dos negros e latinos dos Estados Unidos, mostrando que todos esses grupos sofrem problemas de saúde semelhantes decorrentes do racismo. Portanto, os processos e resultados apontados não podem ser consequências das peculiaridades de um grupo específico, por mais que o grupo dominante prefira atribuir esses problemas de saúde às supostas deficiências culturais dos grupos afetados.

Os autores apontam a necessidade de mais estudos do curso de vida, porque as experiências de discriminação e humilhação racistas das crianças podem ainda afetar sua saúde décadas depois. Além disso, existem múltiplos caminhos indiretos que relacionam o racismo à saúde, por meio da restrição de oportunidades educacionais e econômicas, da exposição à violência ou a contaminantes no ambiente, ou dos transtornos mentais e das alterações comportamentais, como, por exemplo, regimes alimentares pouco saudáveis ou o uso de tabaco, álcool ou outras drogas. Nesses processos, o racismo interage com outros riscos à saúde ao longo do tempo. Além do mais, os indivíduos não existem de forma independente; o racismo sofrido por um influencia também os outros ao seu redor, fenômeno particularmente evidente no caso dos filhos de vítimas de racismo. Somente estudos que seguem os mesmos indivíduos e famílias por bastante tempo permitem a compreensão das complexidades envolvidas nessas relações.

Ludger Pries é professor de sociologia na Ruhr Universität Bochum, Alemanha, onde detém a cátedra Sociologia/Organização, Migração, Participação. Ele é um dos principais pesquisadores de questões relacionadas à imigração na Europa. No seu artigo com Natalia Bekassow, aluna de pós-graduação na mesma universidade, situa as discussões e pesquisas sobre o racismo no contexto do pós-guerra, enfatizando como o desastre 
do nazismo influencia os entendimentos do racismo na Europa até hoje. Os autores também descrevem a estrutura de agências e leis da União Europeia que visam proteger os direitos humanos básicos e monitorar e coibir o racismo e a discriminação contra diversos grupos de minorias e imigrantes, além da discriminação baseada em outras características, como o gênero, a orientação sexual ou a presença de deficiências. Essa estrutura é complexa em função da necessidade de harmonizar as leis e agências de muitos países distintos. A mesma complexidade inibe a coleção de dados realmente comparáveis entre os estados integrantes da UE. Boa parte do problema decorre das diferenças entre países nos conceitos de racismo e nas definições operacionais usadas nas pesquisas. Os autores incluem uma ampla discussão das várias fontes de dados quantitativos, e alguns com dados qualitativos, para pesquisas sobre o racismo na UE, bem como das suas possibilidades e limitações. Essa discussão deve ser bastante útil para aqueles que pretendem desenvolver pesquisas comparativas com países europeus.

Os autores também resumem várias pesquisas sociocientíficas sobre a prevalência e as formas do racismo na Europa hoje, e sobre mudanças no preconceito contra grupos específicos. Alguns resultados são claros. Em toda a Europa os roma ("ciganos") constituem o grupo que sofre o maior grau de estigmatização e discriminação. A experiência e percepções dos roma mesmos e dos outros são coerentes nesse ponto. Entre grupos étnicos, os africanos negros do sul da Saara estão em segundo lugar na escala dos estigmatizados na Europa. De maneira geral, os imigrantes de outros países da UE não sofrem muita discriminação, embora sejam mais numerosos que os outros imigrantes em quase todos os países da região. Existe, também, uma leve tendência, na maioria dos países, para a diminuição do racismo. Entre os grupos religiosos, são os muçulmanos que sofrem de longe o maior grau de preconceito, resultado que não deve ser 
surpreendente para ninguém, embora o antissemitismo ainda persista na Europa. Vários grupos de ultradireita combinam a hostilidade aos muçulmanos com o antissemitismo. Sabe-se também - embora os autores não discutam isso - que alguns muçulmanos europeus se atraem por elementos do antissemitismo europeu. $\mathrm{O}$ anti-islamismo é particularmente forte na França, e bem mais fraco na Alemanha, apesar da grande população muçulmana deste último país. O artigo alerta que, apesar de todos os esforços da UE para proteger os direitos básicos e combater a discriminação, o racismo continua sendo um problema sério na região, que se reflete no apoio crescente aos partidos populistas e anti-imigração da direita.

Ainda há muito para pesquisar sobre as diferenças entre as formas e a força da discriminação contra grupos específicos, e sobre as diferenças entre países e entre regiões dentro dos países. Por exemplo, é importante entender por que o movimento anti-islâmico PEGIDA, discutido pelos autores na introdução do artigo, é mais forte na cidade de Dresden, justamente uma das cidades alemães com menor presença muçulmano, ao passo que cidades com populações muçulmanos muito maiores, como Berlin ou as cidades da região industrial do vale do Ruhr, têm movimentos anti-islâmicos muito mais fracos, que encontram bem mais oposição que apoio entre as populações locais.

Melissa F. Weiner é professora de Sociologia na College of the Holy Cross, uma faculdade jesuíta no estado de Massachusetts, EUA. Sua contribuição a este número analisa as representações da escravidão, da imigração e da África encontradas nos livros escolares de história publicados na Holanda nas últimas décadas. O caso da Holanda é particularmente interessante a esse respeito, porque o país já foi uma grande potência colonial, profundamente engajada no tráfico de escravos e com várias colônias escravistas no Caribe, além da dominação secular da Indonésia, de sua colônia na África do Sul e de sua malfadada aventura no nordeste 
brasileiro. Entretanto, os holandeses hoje nutrem uma autoimagem de tolerância multicultural, pacifismo e colaboração internacional, em evidente contraste com outros países ocidentais mais abertamente racistas e belicosos. Para manter essa autoimagem de pequeno país igualitário, aberto e tolerante, o discurso público dos holandeses tende a desenfatizar o seu passado imperialista e escravista, operando o esquecimento social dos aspectos do passado incoerentes com sua autoimagem, o que produz consequências reais no presente, porque condiciona as relações dos holandeses brancos com a grande população de imigrantes não brancos e descendentes presente no país.

Weiner aborda um aspecto central desse processo de amnésia social, que são as representações da escravidão, da África e dos imigrantes não brancos nos livros escolares holandeses. Baseando-se na análise de conteúdo de todos os livros escolares de história para o primeiro grau publicados nas últimas décadas, Weiner argumenta que os livros escolares sistematicamente suavizam suas representações da escravidão, apresentam os africanos como selvagens primitivos, salientam os pontos de vista dos holandeses escravistas e colonialistas, e não dos africanos ou outros povos colonizados, e apresentam os imigrantes não brancos recentes como problemáticos e aproveitadores da generosidade holandesa, sem reconhecer qualquer vínculo entre o passado colonialista e a imigração recente.

Elaine Meire Vilela, professora de Sociologia na Universidade Federal de Minas Gerais, especializada em demografia social e estudos da imigração, e Karl Monsma, professor de Sociologia da Universidade Federal do Rio Grande do Sul, especializado na sociologia histórica do racismo e da imigração, contribuem com um artigo avaliando as possíveis consequências das migrações internas para a desigualdade racial no local de destino dos migrantes, focalizando especificamente a migração interestadual para o interior do estado de São Paulo e suas consequências para as 
desigualdades raciais entre paulistas. Existe uma literatura internacional mostrando que a imigração geralmente estimula a economia do país de destino, beneficiando especialmente a elite e a classe média, ao mesmo tempo em que pode prejudicar os mais pobres, especialmente os integrantes de minorias racializadas e discriminadas, que precisam competir com imigrantes de maneira relativamente direta no mercado de emprego. Existem vários motivos, além do racismo puro, para os empregadores preferirem os imigrantes. Em função da seletividade das migrações, os migrantes em geral são particularmente motivados, saudáveis e laboriosos; em função das diferenças salariais entre os lugares de origem e destino, e, em muitos casos, a falta de direitos no país de imigração, os imigrantes geralmente aceitam salários e condições de trabalho inaceitáveis para os trabalhadores nativos, e são menos propensos a se organizar em sindicatos para lutar por condições melhores.

Boa parte da literatura pertinente focaliza as consequências da imigração para os negros e outras minorias dos Estados Unidos. As pesquisas empíricas evidenciam grandes benefícios econômicos da imigração, especialmente para a classe média e a elite, mas os resultados geralmente mostram prejuízos para minorias nativos pobres, tendência particularmente forte em certos setores específicos, onde em poucos anos os empregadores podem substituir quase todos os trabalhadores negros por imigrantes. Todos os motivos mencionados acima para os empregadores favorecerem migrantes internacionais também se aplicam aos migrantes internos, menos a ausência de direitos no local de destino. Os autores estimam modelos estatísticos hierárquicos a partir de dados do censo de 2010 para avaliar se a presença de mais migrantes de outros estados aumenta a desigualdade de renda entre negros e brancos paulistas. Os resultados confirmam que a imigração aumenta a renda da população nativa de maneira geral e possivelmente amplia um pouco a desigualdade racial, 
mas esse último efeito é fraco e não significante. Ainda há muito para pesquisar a respeito das relações entre as migrações e o racismo. É comum pensar os migrantes e imigrantes simplesmente como vítimas do racismo, mas como este artigo, e a história da imigração europeia ao Brasil, nos lembram, os migrantes também podem ganhar certas vantagens sobre as minorias nativas e até participar do racismo dos grupos dominantes.

Considerados em conjunto, os artigos deste dossiê mostram que o racismo toma várias formas e permeia quase todos os aspectos das sociedades racistas. Portanto para realmente acabar com o racismo as políticas públicas e outras iniciativas precisam focalizar vários aspectos do fenômeno ao mesmo tempo. Somente cotas nas universidades públicas e a criação de uma classe média negra, embora importantes, não serão suficientes, por si sós, para superar o racismo. Cinquenta anos de várias formas de ações afirmativa nos Estados Unidos - no ensino superior e também no mercado de trabalho - devem ser suficientes para mostrar que as cotas não constituem a panaceia que alguns parecem pensar. Naquele país existe hoje uma classe média negra razoavelmente grande, embora ainda menor, proporcionalmente, do que a classe média branca. Entretanto, a maioria da população negra continua a sofrer a pobreza, o desemprego, a violência policial e o encarceramento, entre outros problemas sociais, a taxas bem maiores que a população branca. Várias análises mostram que a crise financeira de 2008 e o estouro da bolha imobiliária naquele país prejudicaram mais as famílias negras do que as brancas, o que aumentou a desigualdade racial na riqueza, que já era bem maior que a desigualdade de renda.

Embora alguns possam ver a continuidade da desigualdade racial nos EUA como evidência do fracasso de políticas de ação afirmativa, é mais acertado perceber esta situação como evidência do sucesso limitado dessas políticas. As várias formas de preferência para negros nas universidades e no emprego foram um sucesso na criação de uma classe média 
negra, mas deixaram quase intocadas várias formas do racismo, especialmente a segregação residencial, que, como argumentam Williams e Priest, origina vários dos problemas e desvantagens que afligem as comunidades de negros e outras minorias. Isso não é um argumento contra as cotas no ensino superior; é um argumento a favor de mais intervenções em vários aspectos da vida social para combater o racismo e garantir oportunidades iguais para os negros e para outras populações historicamente racializadas e estigmatizadas, que no Brasil seriam principalmente os povos indígenas, mas podem incluir outros grupos, como, por exemplo, os refugiados.

Os artigos salientam vários aspectos do racismo que devem ser levados em conta nas políticas públicas, no sistema educacional e na vida cotidiana de qualquer cidadão que se importa com a construção de uma sociedade justa, especialmente, nos artigos de Lempert e de Williams e Priest, a importância de bairros, escolas, universidades, lugares de trabaIho e serviços públicos onde os integrantes de grupos racializados podem se sentir seguros e respeitados - ou seja, espaços livres da violência racial física e simbólica, o que é essencial para a proteção da autoestima e o desenvolvimento da confiança e das capacidades necessárias para o sucesso educacional, profissional e pessoal. A pessoa sujeita repetidas vezes à discriminação racial e à consequente humilhação, como mostram Williams e Priest, facilmente desenvolve problemas mentais e alterações comportamentais que são destrutivas para si mesmo e para sua comunidade. Podemos acrescentar que tais problemas, por sua vez, reforçam os estereótipos dos grupos subordinados e as tendências para a discriminação racial entre a população dominante, em um círculo destrutivo que não é fácil de interromper.

Por outro lado, a miséria e a violência estão tão presentes em muitas das comunidades onde se concentram os negros ou outros grupos étnicos estigmatizados - como, por exemplo, os roma em vários países europeus 
- que parece um milagre que nem todos os moradores sofrem de transtornos mentais ou manifestam comportamentos antissociais. É igualmente importante entender a gênese da força e resistência que muitos povos racializados também manifestam, porque as intervenções mais eficazes para a promoção da igualdade racial devem partir das instituições, redes e práticas que já servem para conservar a dignidade e facilitar a sobrevivência e a resistência dos povos racialmente subordinados - como, por exemplo, famílias, organizações religiosas, redes informais de mulheres e fenômenos culturais como a música e a dança.

Uma das vantagens da pesquisa comparativa ou internacional é que conduz ao questionamento de categorias hegemônicas no contexto de origem do pesquisador. As evidências europeias discutidas por Pries e Bekassow, por Weiner e por Williams e Priest apontam, pelo menos implicitamente, alguns limites da maneira predominante de pensar o racismo e as "raças" no Brasil e em boa parte da América, centrada na cor da pele e outras características físicas. É lugar comum nos círculos acadêmicos e de ativistas na América pensar a racialização do mundo como consequência da expansão europeia da época moderna e da subjugação de outros povos, com características físicas diferentes, pelos europeus, especialmente a escravização de africanos. Entretanto, o antissemitismo, provavelmente a forma mais velha do racismo europeu, tem pouco a ver com diferenças físicas e antecede as descobertas do final do século XV e a dominação do resto do mundo pelos europeus. O racismo anti-roma, apontado em várias pesquisas discutidas por Pries e Bekassow como o mais forte de todos os racismos europeus, também se originou antes do imperialismo europeu moderno, porque os roma, grupo migratório originário do subcontinente indiano, já estavam presentes na Europa na época medieval e a perseguição a eles antecede a expansão europeia. O preconceito europeu contra os muçulmanos também antecede a época moderna, originando-se dos 
conflitos entre impérios cristãos e muçulmanos ao redor do Mediterrâneo. Certamente o anti-islamismo europeu cresce hoje em função da imigração e da violência recente, que têm muito a ver, sim, com a história do imperialismo europeu e norte-americano no Oriente Médio, mas cresce a partir de preconceitos já existentes. $\mathrm{O}$ anti-islamismo também se baseia principalmente em características culturais, não em diferenças fenotípicas. Muitos muçulmanos árabes ou de outras origens, como a Turquia ou a Irã, têm a pele clara e geralmente são considerados brancos.

A evidência europeia aponta a necessidade de outra definição do racismo, centrado na essencialização e dominação de um povo por outro, não em diferenças físicas. A dominação de boa parte do mundo pelos europeus, e posteriormente pelos norte-americanos, originou boa parte do racismo do mundo atual, mas não é a única origem do racismo, e novos racismos sempre podem surgir, como, por exemplo o que se evidencia na violência recente de sul-africanos contra migrantes moçambicanos.

Os artigos de Feres e de Weiner enfatizam os aspectos representacionais do racismo. As representações públicas - por exemplo, na mídia, nos discursos políticos e nos livros escolares - de grupos racializados reforçam estereótipos e a estigmatização ao mesmo tempo em que moldam a autoimagem dos grupos dominantes. Com o complexo interligado de, por um lado, os resultados do racismo, como a pobreza e os problemas sociais, e, por outro lado, as representações negativas dos grupos racializados, que parecem ser coerentes com a realidade observada, os grupos dominantes naturalizam os estereótipos negativos dos povos subordinados. Por exemplo, o fato dos bairros com alta concentração de negros muitas vezes sofrerem da violência permite que brancos internalizem sem questionamento o estereótipo do negro violento. Por um truque de inversão da ordem causal, o branco se engana, convencendo-se que é a natureza do negro, e não o racismo, que origina a violência observada. Tal 
inversão se facilita pelos estereótipos raciais amplamente difundidos na esfera pública. Uma vez que os estereótipos raciais se internalizam, constituem uma lente pela qual o grupo dominante percebe vários aspectos da desigualdade racial, permitindo que se exima da responsabilidade. Por exemplo, na comparação do negro local com os migrantes internacionais ou nacionais, os brancos geralmente não percebem a seletividade das migrações, enfatizada no artigo de Vilela e Monsma; em vez disso, tendem a perceber o sucesso maior dos migrantes como evidência dos defeitos dos negros. Para romper as tendências para as representações e a realidade observado do ponto de vista dos dominantes se reforçarem mutuamente, é importante produzir representações mais acertadas de toda a história das relações entre os povos dominantes e os outros por eles racializados, e de enfatizar múltiplos pontos de vista a respeito dessas relações, sobretudo os pontos de vista dos povos subordinados. ${ }^{2}$

O intuito deste dossiê é estimular o debate, não oferecer soluções fechadas e fáceis. Sem dúvida há, também, muitos outros aspectos do racismo que poderiam ser abordados - como por exemplo as maneiras em que a internet facilita a elaboração e propagação de novas ideologias racistas e a formação de redes de racistas de vários tipos. Ainda há muito para pesquisar, também, a respeito dos cruzamentos do racismo com outras formas de estigmatização e exclusão, como gênero, sexualidades e nacionalidade.

\footnotetext{
${ }^{2} \mathrm{O}$ que é bem diferente de produzir versões simplistas e maniqueístas da história, idealizando os povos subordinados e as terras das suas origens, como parece ser o caso de boa parte da literatura "afrocentrista". Para este autor, é um insulto às capacidades intelectuais dos povos racializados tratá-los como se não fossem capazes de compreender a complexidade e as contradições dos processos históricos.
} 
Sociologias, Porto Alegre, ano 17, no 40, set/dez 2015, p. 14-32

Se este dossiê provocar novas maneiras de pensar sobre o racismo e abrir o caminho para novos projetos de pesquisa, terá cumprido sua missão.

Karl Martin Monsma é PhD em Sociologia pela Universidade de Michigan (EUA) e Professor do Programa de Pós-Graduação em Sociologia da Universidade Federal do Rio Grande do Sul. \} \text { karlmonsma@hotmail.com } 